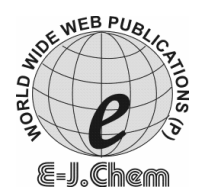

http://www.e-journals.net
ISSN: 0973-4945; CODEN ECJHAO

E-Journal of Chemistry 2010, 7(3), 693-700

\title{
Resistivity Study of Shallow Aquifers in the Parts of Southern Ukanafun Local Government Area, Akwa Ibom State, Nigeria
}

\author{
N. J. GEORGE, A. E. AKPAN and I.B. OBOT* \\ Department of Physics, University of Calabar, Nigeria. \\ *Department of Chemistry, University of Uyo, Nigeria. \\ proffoime@yahoo.com
}

Received 19 May 2009; Revised 25 July 2009; Accepted 20 September 2009

\begin{abstract}
A resistivity study by vertical electrical sounding (VES) employing the Schlumberger electrode configuration has been used to delineate shallow aquifers in some villages in Southern Ukanafun Local Government Area of Akwa Ibom State, Southern Nigeria. The information realized from the resistivity data and nearby logged boreholes show that the depths penetrated by currents were all sandy formations with various thicknesses. However, the main aquifers comprise within the maximum current penetration, very coarse - grained (gravelly) sand and fine sand with resistivity in the ranges of 4680-30700 $\Omega \mathrm{m}$ and $207-2530 \Omega \mathrm{m}$ and thickness in the ranges of 43-63 $\mathrm{m}$ and 18-40 m respectively. The aquifers with minor hydraulic gradient are separated by thin beds of clay according to lithology logs and these beds were masked in the sounding data due to the principle of suppression.
\end{abstract}

Keywords: Ukanafun, Aquifer, Gravelly sands, Resistivity.

\section{Introduction}

Water is one of the essential natural endowments that is needed by all. Over the years, towns and villages rely on the surface water for their daily needs. Their needs of water in this direction range from domestic to industrial levels. Contemporary researches have confirmed that the surface water resources are degraded by dissolved contaminants emanated from man's activities ${ }^{1}$. However, underground water can be utilized as good quality water if it is not soiled by man's deliberate or in deliberate activities. A good knowledge of the effects 
of the contaminants of surface water on public health is a driving force that provokes the search for other sources of water that are devoid of contaminations. Several enlightenment programmes mounted by public health workers, non-governmental organizations and other concerned bodies have helped in advising the rural people to change from surface water which is degraded in many aspects, to other sources of water especially groundwater. Groundwater is not ubiquitous though it is fairly distributed all over the world. The presence of groundwater in economic quantity in a particular area can be ascertained by using reliable geophysical techniques such as vertical electrical sounding (VES) or seismic method. This is because wildcat drilling to authenticate the availability of groundwater may be expensive and time consuming ${ }^{2-4}$.

In this work, VES method was used to delineate the shallow aquifers in some villages in Southern Ukanafun Local Government Area of Akwa Ibom State, Nigeria. The goal of this set of investigations is to fill the information gap by providing the necessary information regarding the exploration and exploitation of groundwater in Southern Ukanafun Local Government Area and its environs.

The geology of the area is Recent to Tertiary sediments belonging to the Benin Formation. This formation is the youngest geologic unit in the Niger-Delta Sedimentary Basin. This formation comprises continental sand and gravel, deposited in an upper deltaic plain environment. The grain sizes range from coarse to fine in texture and are poorly sorted ${ }^{5}$. They are also thick and friable with minor intercalations of clay, silts and sandstones in the area mapped. The alternative sequence builds up multiple-aquifer systems with various thicknesses ${ }^{2-4}$. Thus, the aquifer systems have been found to be a combination of the different grain sizes of sand.

The mapped area which sits on a relatively flat terrain is drained by the Kwa Ibo River. It has a humid tropical climate characterized with two distinct seasons - the wet and dry seasons. It is hoped that the data and the conclusions derived from the research will serve as an information pool to developers and intended developers on what the optimum depth of a functional borehole should be and the type of rock that will host the good quality water. The results of this research represent only the interpretation of data which were gathered in a scientific manner.

\section{Experimental}

The locations selected for the investigation cover seven villages in Southern Ukanafun Local Government Area, Akwa Ibom State, Nigeria. The seven villages include Edem Idim, Ikot Inyang Udo, Ikot Odiong, Ikot Enang, Idung Udo, Ikot Akpan Eyara and Ikot Udo Obobo. These villages lie between latitude $4^{\circ} 55^{\prime} \mathrm{N}$ and latitude $5^{\circ} 00^{\prime} \mathrm{N}$ and longitude $7^{0} 30^{\prime} \mathrm{E}$ and longitude $7^{0} 40^{\prime} \mathrm{E}$ in Akwa Ibom State of Nigeria (Figure 1).

At the field, vertical electrical sounding (VES) method employing Schlumberger electrode configuration was used to take eighteen soundings along a profile that cuts across seven villages mentioned above. The maximum current electrode spread ranged between $600 \mathrm{~m}$ to $800 \mathrm{~m}$ depending on the accessibility of the area, human settlements and other rural infrastructural masts, which posed some barriers to the profile taken. The sounding points were $400 \mathrm{~m}$ apart. Instrument used for the study was a SAS 300 model of ABEM terrameter. Necessary precautionary measures taken to ensure accurate results include wetting the electrodes to ensure proper contacts at all joints, switching off the terrameter and retaking the readings to check polarization of the electrodes, maintaining 
a collinear arrangement of all electrodes at all VES points and ensuring that no green leaf touched the electrodes when measurements were in progress so that currents will not be conducted or leaked away. The plotting of apparent resistivity obtained by multiplying the earth's resistance measured by terrameter with the geometrical factor against the half current electrode potential separation on a bilogarithmic graph was carried out to pre-check the interpretability of the data realized.

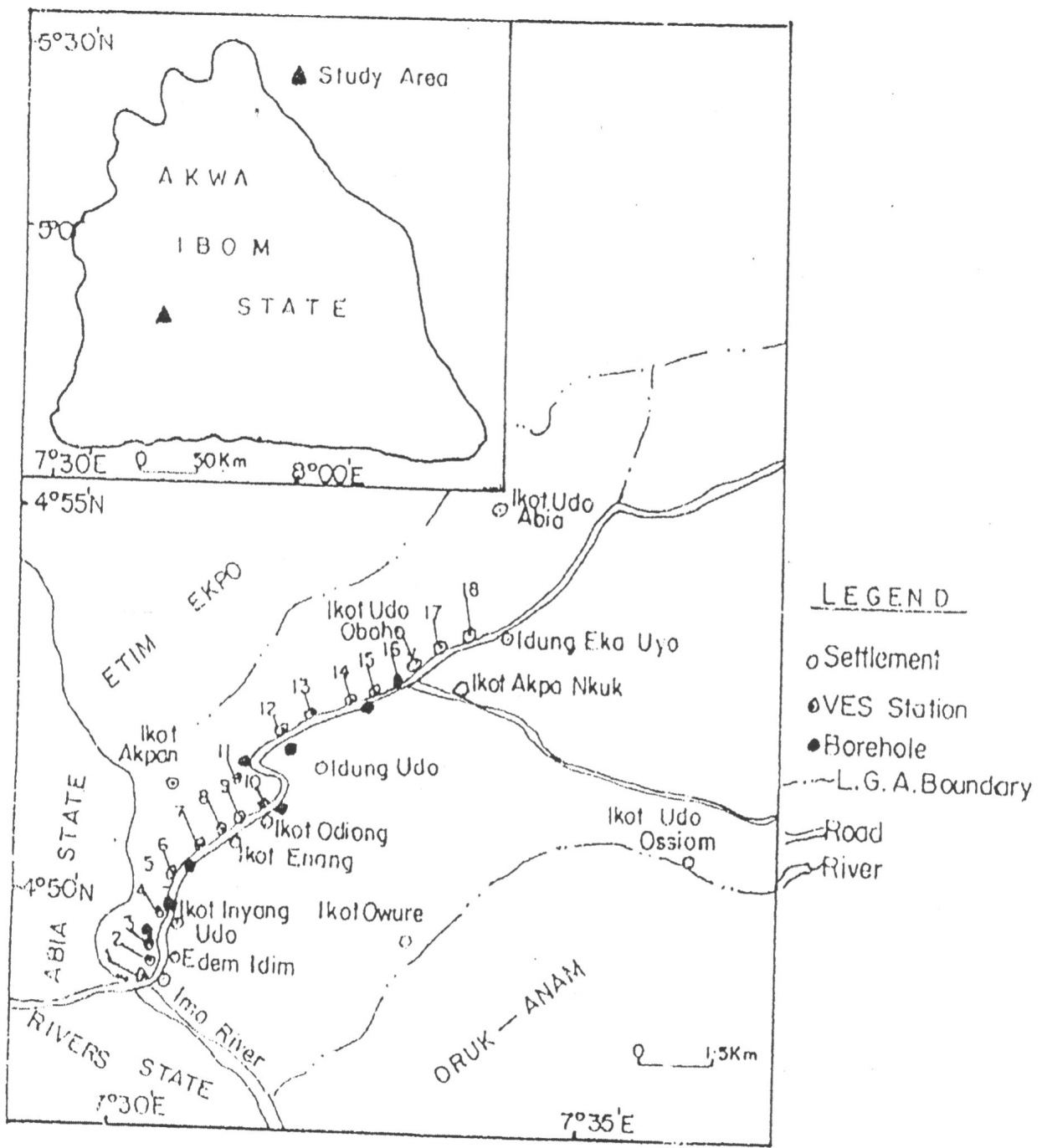

Figure 1. Location map of southern Ukanafun local government area of Akwa Ibom State showing VES and boreholes points.

Data extracted from the plotted graphs were fed into the forward modelling programme developed by Zohdy and Bisdorf ${ }^{6}$. This yielded results that were again fed into the inverse-modelling programme. Results (resistivity and depths) of the models of the area were finally deducted as shown in Table 1. 
Table 1. Summary of geo-electric survey from computer modeling.

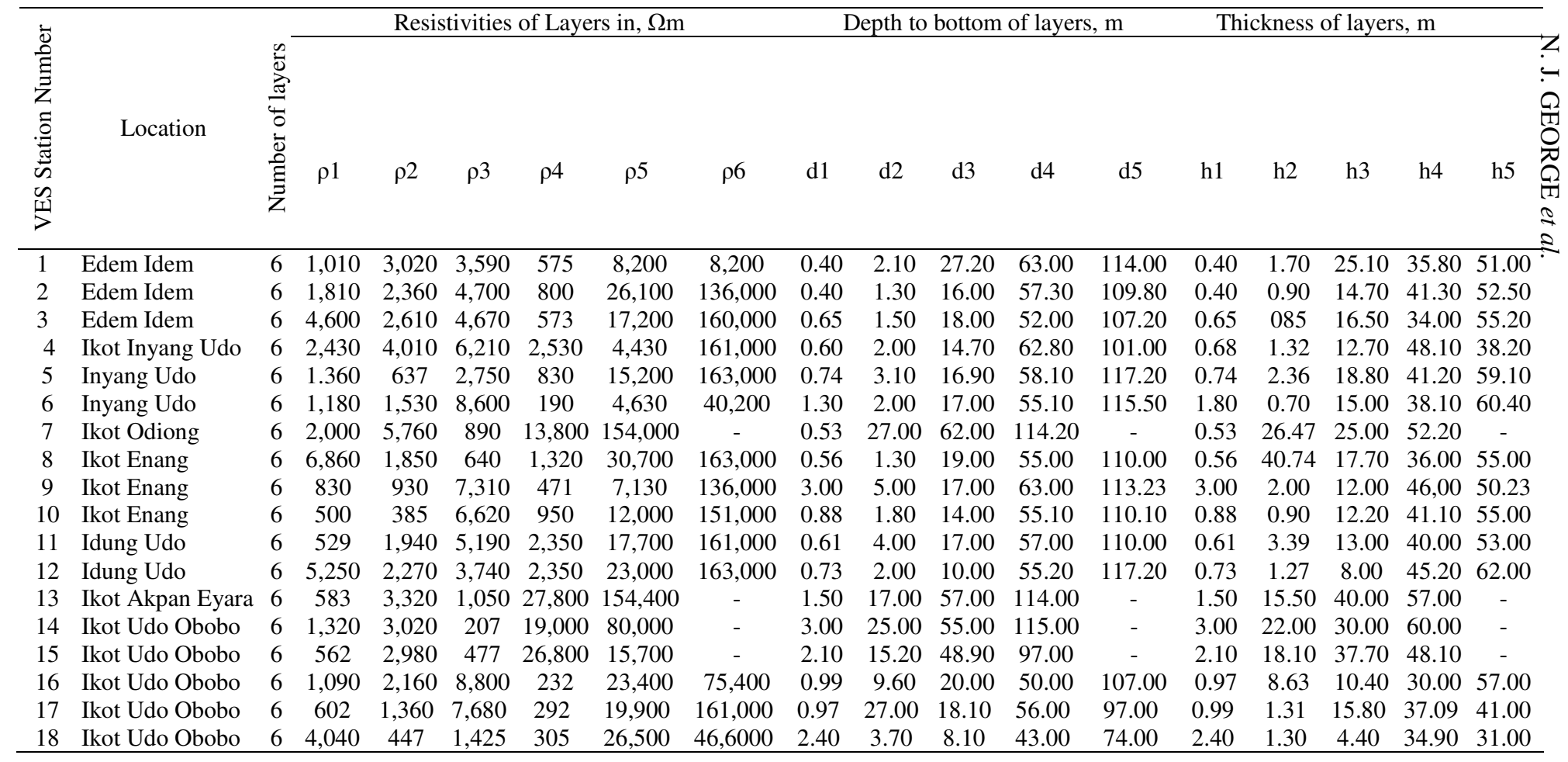




\section{Results and Discussion}

A representative field curve obtained from VES 18 of the study area is shown in Figure 2. Resistivities and depths obtained in the mapped area were plotted along a traverse and a geoelectric section along SW - NE direction drawn in Figure 3 was obtained from Table 2 with the aid of lithologic logs of boreholes in the area. The rock types and resistivity ranges in (Table 2) were obtained through correlations of logged boreholes with the nearby VES stations in the area.

Generally, the resulting sounding curves were unique and the three groups of curves, which show the same shape, are AKHA, HKHA and KHA. (Figure 2). These groups of curves dominate the entire area surveyed.

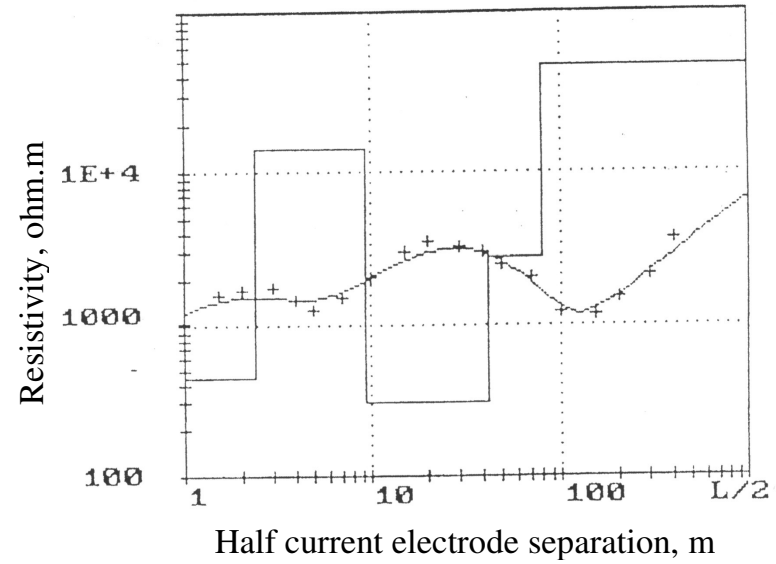

Figure 2. A typical curve (AKHA, KHA and HKHA curve, type) from VES 18 of the study area.

Table 2. Inferred rock matrixes and their corresponding ranges of ressistivity and depthsobtained by correlations of VES and the nearby logged boreholes in the study area.

\begin{tabular}{lcc}
\hline \multicolumn{1}{c}{ Rock Type } & Resistivity, $\Omega \mathrm{m}$ & Depth to bottom of layers, $\mathrm{m}$ \\
\hline Medium grained sand & $385-6860$ & $0.40-3.00$ \\
Medium-coarse grained sand & $1425-8800$ & $0.70-26.47$ \\
Fine sand & $207-2530$ & $4.40-40.00$ \\
Very coarse grained sand (gravelly) & $4680-30700$ & $30.00-60.00$ \\
Sand stone & $15,700-163000$ & $31.00-$ \\
\hline
\end{tabular}

In all, five layers within the maximum electrode separation were identified with each having its distinct thickness and resistivity range as shown in Figure 3.

The first layer, which is medium grained sand, is generally very thin and it overlies the medium-coarse grained sand of the second layer. The second layer identified as medium coarse-grained sand shows an increasing resistivity with depth. The fine sand layer is the third layer that overlies the forth layer identified as very coarse-grained sand. The fine sand layer shows resistivity inversion with depth. The fine sand and the very coarse grained sand layers which are sandwiched with thin bed of clay constitute the major shallow productive aquifers that water is drawn in the study area according to lithological logs (Figure 4). The last layer, which constitutes the bottom layer at the maximum current electrode separation, is sandstone whose thickness cannot be defined within the maximum current electrode separation of this study. 


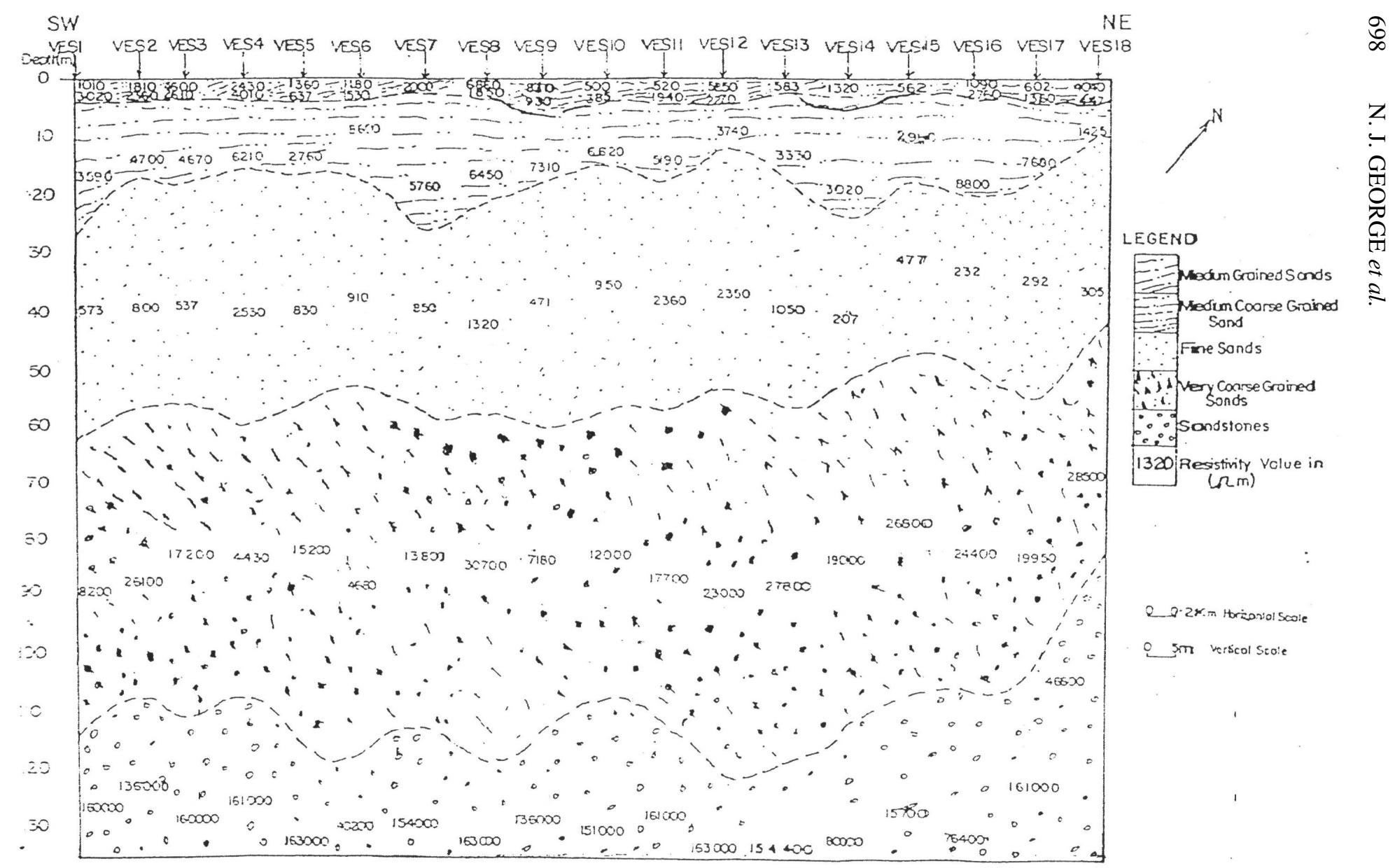

Figure 3. Southwest-Northeast geoclectric section in the study area. 


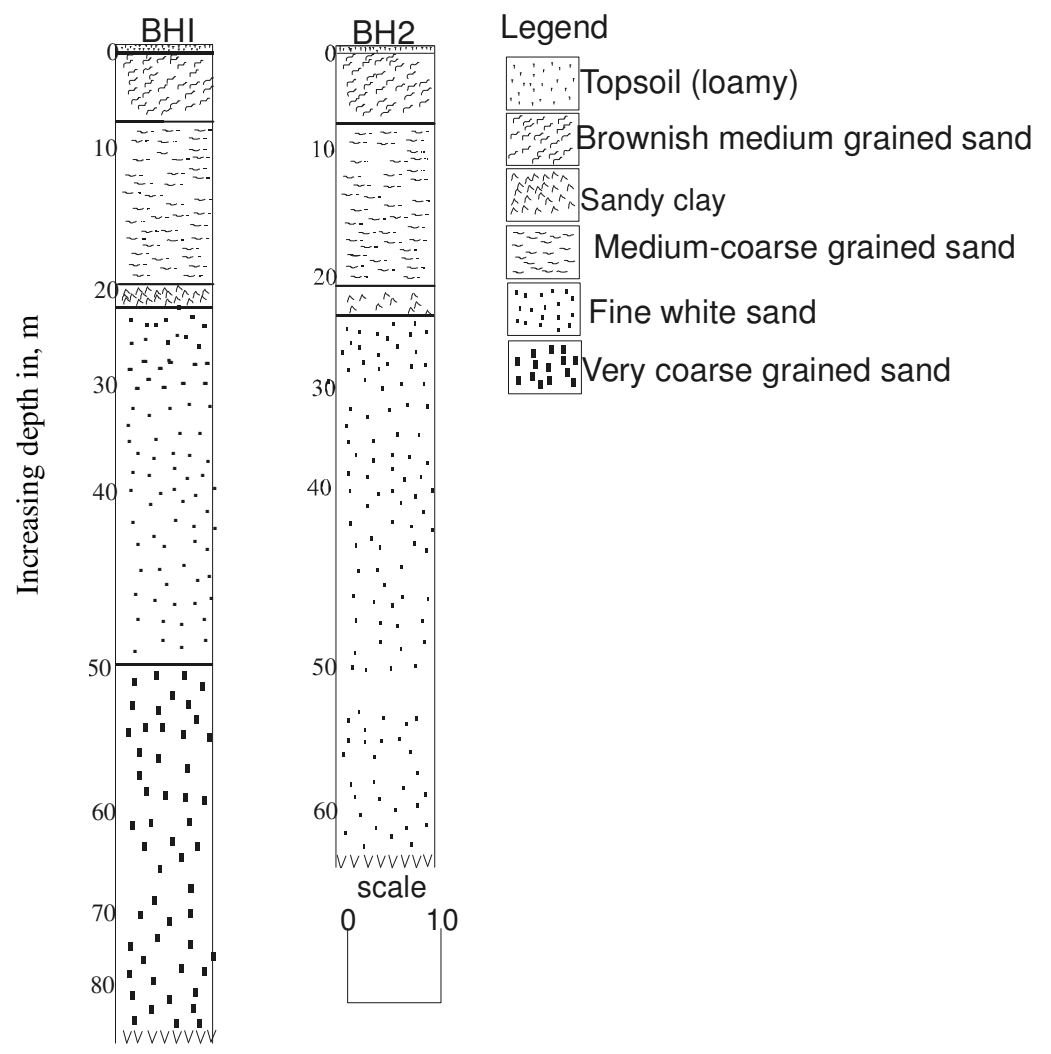

Figure 4. Borehole lithology logs from the study area.

The depth to the first aquifer compares favourably with the static water levels near VES 7 and VES 16, which are $20.16 \mathrm{~m}$ and $18.32 \mathrm{~m}$ respectively. These layers have very good prospect for fresh water based on their high resistivities ${ }^{7,8}$ and the aquifers may not likely to be contaminated with the surface pollution activities due to their depths when compared to the surface. The shallow aquifers are characterized with minor hydraulic gradients due to the minor variation in the static water levels.

\section{Conclusion}

The acquisition of the study area resisitivity data and the attendant interpretation and correlations with drilling logs have allowed the following conclusions to be made.

1. This research which is the first of its kind in the area closes the information gap in terms of geology and hydrogeology.

2. Parts of Ukanafun Local Government Area investigated are composed of mainly continental plain sand, which are medium-grained sand, medium-coarse grained sand, fine sand, very coarse-grained sand and sandstone which are generally called Benin Formation

3. The potential aquifers in the area compose of fine sand and very coarse-grained sand with sizeable thickness that cannot be remarkably influenced by seasonal fluctuations of the water table. 
4. The study area has concealed aquifers separated with thin layers of conductive clayey sand, which are shown only on borehole logs but suppressed in geosection.

5. From the top to the depths where aquifers are located, there may be no possible contamination of water by surface contaminants except from the septic tanks that are deeply seated.

6. The boreholes intended to be sited in the area by individuals, government and nongovernmental organizations should be at the depth not less than $20 \mathrm{~m}$ deep from the surface.

\section{Acknowledgment}

We wish to acknowledge the contributions of late Dr O. N. Etim, who was the Chief Supervisor of the first author when he was a graduate student in Physics Department, University of Calabar, Calabar, Nigeria.

\section{References}

1. Edet A E and Okereke C S, J Afr Earth Sci., 2002, 35, 433.

2. Griffiths R F and King D, Applied Geophysics for Geologists and Engineers Pergamon Press, London. 1985,357.

3. Mbonu P D C, Ebeniro J O, Ofoegbu C O and Ekine A S, Geophysics, 1991, 56(2), 284.

4. $\quad$ Okereke C S, Esu E O and Edet A. E, J Afr Earth Sci., 1998, 27(1), 149.

5. Reijers T J A, Petters S W and Nwajide C S, The Niger Delta Basin, African Basins, Sedimentary Basins of the World, Selley, R. C. (Ed), Elsevier. Holland P, 1997, 151-172.

6. Uchegbu S N, Issues and Strategies in Environmental Planning and Management in Nigeria. Soptlite Publishers, Lagos, 2002, 184.

7. Zohdy A A R and Bisdorf R J, Schlumberger sounding Data Processing and Interpretation program U.S. Geological Survey, 1989, 103.

8. Zohdy A A R, Eaton G P and Maybe D R, Application of surface Geophysics to Groundwater Investigations U.S printing Office, Washington, 1974, 133. 


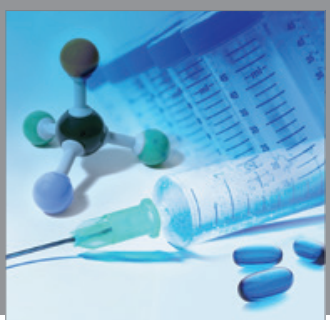

International Journal of

Medicinal Chemistry

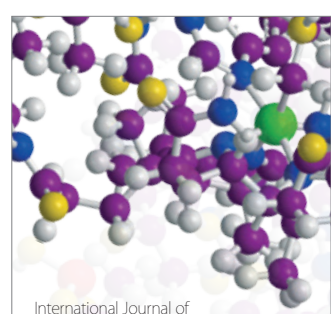

Carbohydrate Chemistry

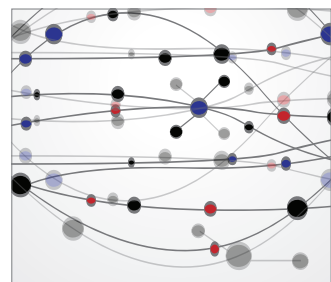

The Scientific World Journal
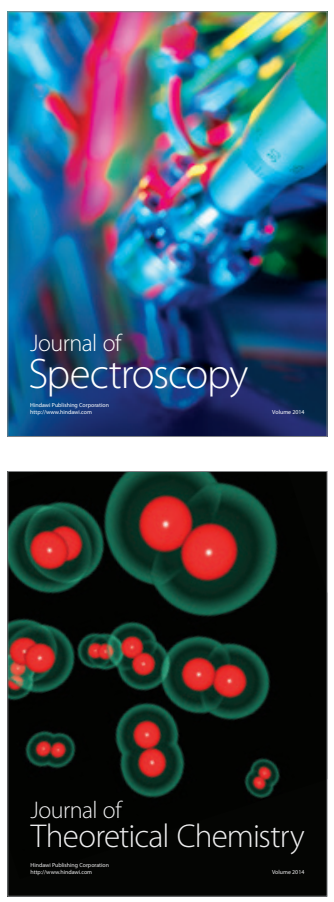
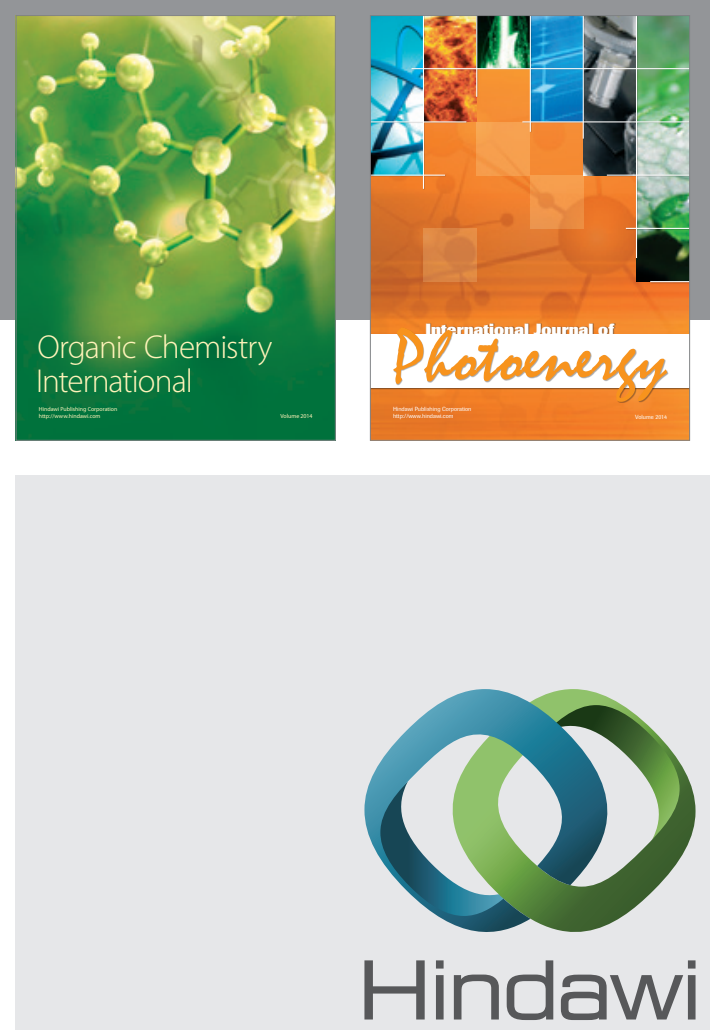

Submit your manuscripts at

http://www.hindawi.com
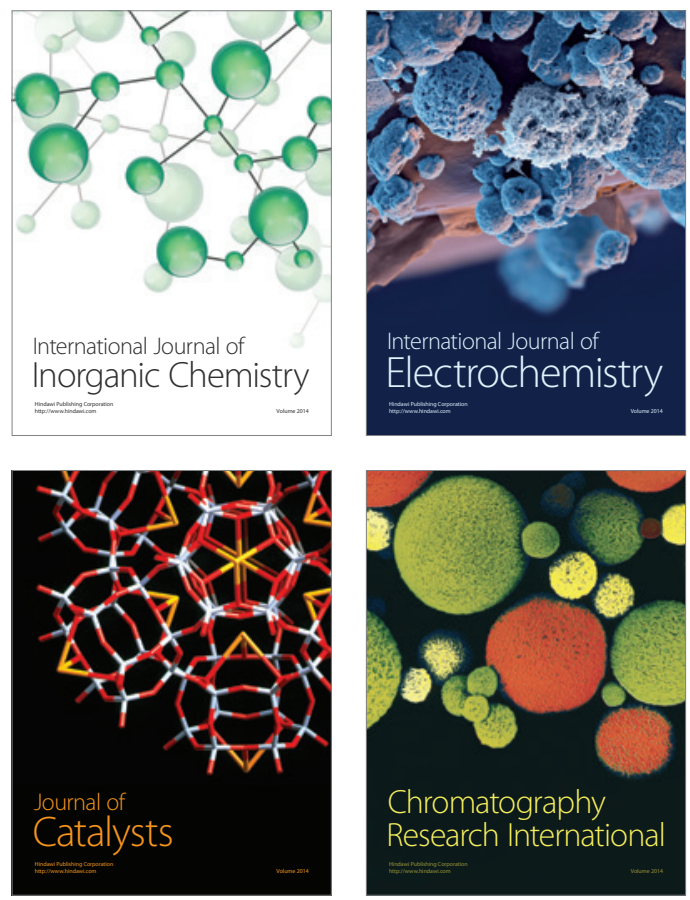
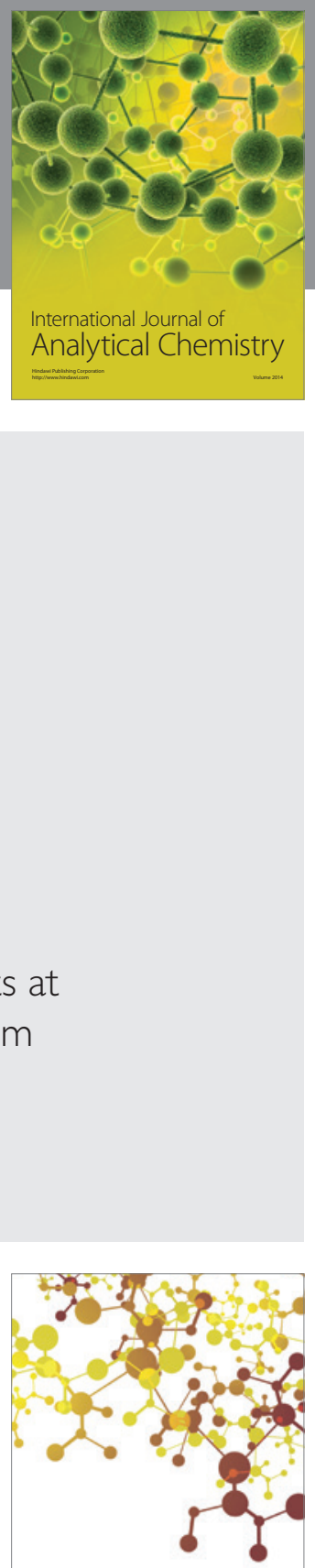

Journal of

Applied Chemistry
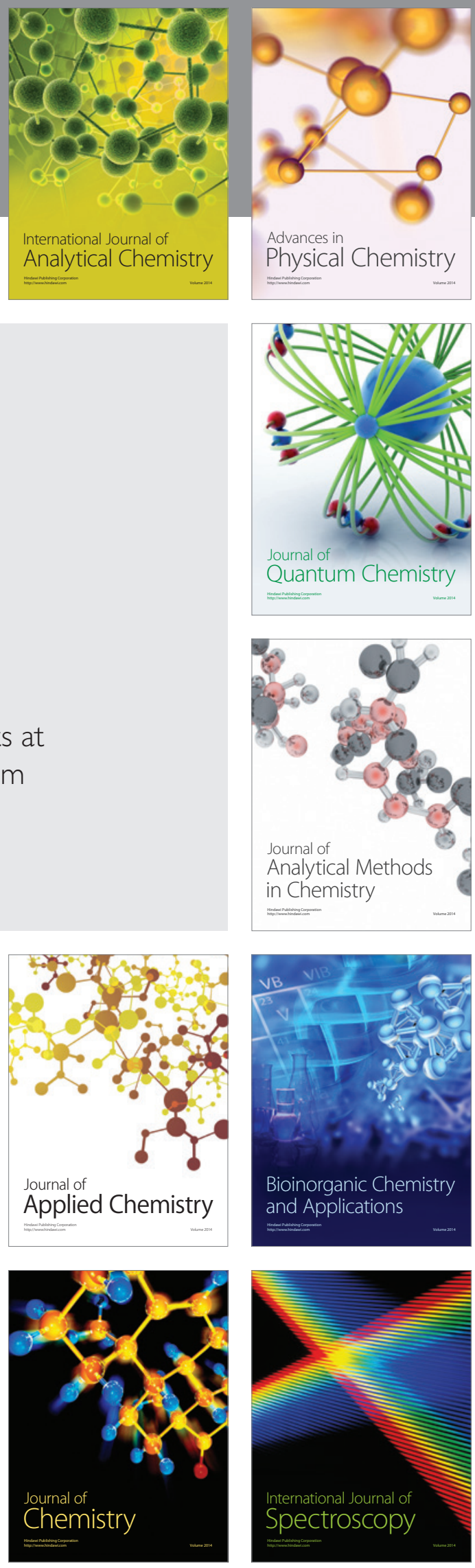